\title{
Cell spheroids are as effective as single cells suspensions in the treatment of critical-sized bone defects
}

Lisa Findeisen ${ }^{1,2^{*} \dagger}$, Julia Bolte ${ }^{1,2 \dagger}$, Corina Vater ${ }^{1,2}$, Cathleen Petzold ${ }^{1,2}$, Mandy Quade ${ }^{2}$, Lars Müller ${ }^{1,2}$, Stuart B. Goodman ${ }^{3}$ and Stefan Zwingenberger ${ }^{1,2}$

\begin{abstract}
Background: Due to their multilineage potential and high proliferation rate, mesenchymal stem cells (MSC) indicate a sufficient alternative in regenerative medicine. In comparison to the commonly used 2-dimensional culturing method, culturing cells as spheroids stimulates the cell-cell communication and mimics the in vivo milieu more accurately, resulting in an enhanced regenerative potential. To investigate the osteoregenerative potential of MSC spheroids in comparison to MSC suspensions, cell-loaded fibrin gels were implanted into murine critical-sized femoral bone defects.

Methods: After harvesting MSCs from 4 healthy human donors and preculturing and immobilizing them in fibrin gel, cells were implanted into $2 \mathrm{~mm}$ murine femoral defects and stabilized with an external fixator. Therefore, 26 14to 15-week-old nu/nu NOD/SCID nude mice were randomized into 2 groups (MSC spheroids, MSC suspensions) and observed for 6 weeks. Subsequently, micro-computed tomography scans were performed to analyze regenerated bone volume and bone mineral density. Additionally, histological analysis, evaluating the number of osteoblasts, osteoclasts and vessels at the defect side, were performed.

Statistical analyzation was performed by using the Student's t-test and, the Mann-Whitney test. The level of significance was set at $p=0.05$.
\end{abstract}

Results: $\mu \mathrm{CT}$-analysis revealed a significantly higher bone mineral density of the MSC spheroid group compared to the MSC suspension group. However, regenerated bone volume of the defect side was comparable between both groups. Furthermore, no significant differences in histological analysis between both groups could be shown.

Conclusion: Our in vivo results reveal that the osteo-regenerative potential of MSC spheroids is similar to MSC suspensions.

Keywords: Critical-sized bone defect, Bone regeneration, Mesenchymal stromal cells, Cell spheroids

\footnotetext{
* Correspondence: lisa.findeisen@tu-dresden.de

+Lisa Findeisen and Julia Bolte contributed equally to this work.

'University Center for Orthopedic, Trauma and Plastic Surgery, University Hospital Carl Gustav Carus, TU Dresden, Dresden, Germany

${ }^{2}$ Center for Translational Bone, Joint and Soft Tissue Research, University Medicine Carl Gustav Carus Dresden, TU Dresden, Dresden, Germany

Full list of author information is available at the end of the article
}

C C The Author(s). 2021 Open Access This article is licensed under a Creative Commons Attribution 4.0 International License, which permits use, sharing, adaptation, distribution and reproduction in any medium or format, as long as you give appropriate credit to the original author(s) and the source, provide a link to the Creative Commons licence, and indicate if changes were made. The images or other third party material in this article are included in the article's Creative Commons licence, unless indicated otherwise in a credit line to the material. If material is not included in the article's Creative Commons licence and your intended use is not permitted by statutory regulation or exceeds the permitted use, you will need to obtain permission directly from the copyright holder. To view a copy of this licence, visit http://creativecommons.org/licenses/by/4.0/. The Creative Commons Public Domain Dedication waiver (http://creativecommons.org/publicdomain/zero/1.0/) applies to the data made available in this article, unless otherwise stated in a credit line to the data. 


\section{Article summary}

Article focus

- This study investigated the osteo-regenerative potential of MSC spheroids in comparison to MSC suspensions in a critical-sized defect.

\section{Key messages}

- The regenerated bone mineral density of the MSC spheroid group is higher than the MSC suspension group.

- The regenerated bone volume of the MSC spheroid group was similar to the MSC suspension group.

- Histological degree of defect healing, as well as bone cell markers, showed no significant difference between the 2 groups.

- Fibrin gel-embedded MSCs, independent of their condition in the gel, are not able to heal a criticalsized defect.

\section{Strengths and limitations of this study}

- MSCs from 4 individual donors, which were genderbalanced (2 male, 2 female), were used. No donordependent effect could be observed as shown in supplementary data.

- A well-established surgical method was used, providing standardized results.

- By using the fibrin gel as an implant, a standardized carrier for cells was provided.

- The number of cells per spheroid might have led to tightened packaging and less available nutrition in the spheroid core.

- No biomechanical testing was performed of dissected femora since defects were not bridged.

\section{Introduction}

Critical-sized bone defects can result from wound infections with extensive debridement, complicated fractures with high bone loss, or tumour resections which are challenging to treat. Implantation of autologous bone, generally harvested from the patient's iliac crest, is still the gold standard because of its favourable osteoconductive, osteoinductive and cellular properties [1]. However, autologous graft is accompanied by disadvantages including potential tissue morbidity and limited bioavailability [2, 3]. Alternatively, bone replacement materials or cell-based therapies might be used due to their promising therapeutic outcomes. Mesenchymal stromal cells (MSCs) are multipotent cells that are located in all organs having connective tissue [4], including adult bone marrow, umbilical cord blood, fetal liver and fat [5-7]. Their osteogenic potential is based on the high proliferation rate, low immunogenicity and their multilineage capacity $[4,8,9]$. Therefore, functional cells like osteoblasts and chondrocytes can be released at the defect side. Defect healing is improved by the secretome of MSCs, consisting of growth factors, cytokines and angiogenic factors [10]. Cryopreserved cells can certainly be used, since preservation and thawing do not influence growth and osteogenic differentiation [11]. However, disadvantages of MSCs have been revealed, such as the difficulty of maintaining cell functions, the attachment to host cells, as well as their low survival rate during transplantation [12-14]. The unphysiological microenvironment, originating from culturing cells with the commonly used 2-dimensional culture technique, might be an explanation for these disadvantages [15]. Attempts have been made to imitate the complex, physiological milieu of cells and tissues, leading to the development of 3-dimensional culture systems. In this regard, increased overall functions could be observed when forming multicellular aggregates, as cell-cell interactions are improved [16-18]. MSC spheroids show enhanced osteoinductive properties in vivo and in vitro due to their interaction with an endogenous environment and extracellular matrix and their retainment of osteogenic differentiation $[16,19-21]$. Furthermore, the unique culture geometry also induces anti-inflammatory, anti-apoptotic and proangiogenic effects $[17,18,22-24]$. Osteogenesis and angiogenesis promoting properties are required in particular by pathological bone healing, for example when avascularity and hypoxia occur in large bone defects [25]. All in all, these improvements might be beneficial to the treatment of critical-sized defects with their relatively harsh microenvironment. There are several definitions for a critical-sized bone defect. In general, for segmental bones the length of a critical-sized defect is about 1.5 times the diameter of the respective bone [26]. When establishing the murine femoral critical-sized bone defect model, which is used in this study, we could show that in the $2 \mathrm{~mm}$ defect group only 3 out of 8 bones healed [27]. Therefore, we have chosen the $2 \mathrm{~mm}$ defect. Furthermore, when the defect was filled with a cell-free mineralized collagen scaffold, we could not observe sufficient bone growth in previous studies [28].

We hypothesized that MSC spheroids would show a higher bone regenerative potential in a critical-sized femoral bone defect model in mice compared to MSC suspensions.

\section{Material and methods Study design}

Firstly, to immobilize the cells within the defect they were encapsulated in fibrin gels. Therefore, bone marrow aspirates were harvested from healthy human donors undergoing total hip arthroplasty. After isolation of 
the MSCs, cryopreservation and thawing, MSCs were cultured and pre-differentiated in osteogenic medium. Cells were divided in 2 groups (MSC spheroids, MSC suspensions) and generated implants underwent a qualitative live-dead staining test. To verify the survival rate of cells in vivo is a major challenge. To show that spheroidal and suspension cells immobilized within the fibrin gel were alive at the time of implantation, we performed live/dead staining. MSC spheroids were encapsulated into the fibrin gels after 9 days of culture; MSC suspensions were encapsulated after 10 days (Fig. 1).

Secondly, $26 \mathrm{nu} / \mathrm{nu}$ NOD/SCID nude mice were randomized into 2 groups (MSC spheroids, MSC suspensions). A critical-sized defect of $2 \mathrm{~mm}$ was created on the right femur of all animals and stabilized with an external fixator. The fibrin gel was implanted into the defect according to group allotment. After an observation period of 6 weeks, animals were euthanized and highresolution micro-computed tomography $(\mu \mathrm{CT})$ as well as histological analysis were performed on all explanted right femora.

\section{Preparation of MSCs}

MSCs were isolated after informed consent (ethics approval number: EK91032012) from human bone marrow aspirates of 4 healthy donors ( 2 male: 70 and 71 years old, 2 female: 71 and 79 years old) undergoing total hip arthroplasty by density gradient centrifugation (FicollPaque Plus, GE Healthcare, $1.077 \mathrm{~g} / \mathrm{ml}$, Little Chalfont, United Kingdom) and subsequent plastic adherence. Due to logistic reasons and to make culture conditions comparable, cyropreserved cells were used for implant preparation. Therefore, MSCs of passage 2 were thawed and cultured in basic medium (DMEM, 15\% FCS, 1\% penicillin/streptomycin) for 3 to 4 days until they reached confluency. Then, basic medium was changed to osteogenic medium (DMEM, 10\% FCS, 1\% penicillin/ streptomycin, $100 \mathrm{nM}$ dexamethasone, $10 \mathrm{mM}$ betaglycerolphosphate, $50 \mathrm{mM}$ ascorbic acid-2 phosphate) for osteogenic pre-differentiation for 7 days. Exchange of medium was performed twice a week.

\section{Mesenchymal stem cell spheroid formation}

The pre-differentiated cells were detached from the culture flasks using $0.5 \%$ trypsin/ ethylenediaminetetraacetic acid (EDTA), counted and resuspended in osteogenic medium to obtain a single cell suspension with a concentration of $0.2510^{6} / \mathrm{ml} .200 \mu \mathrm{l}$ of this cell suspension (= $510^{4}$ cells) were added per well to a 96-well suspension plate (Sigma-Aldrich, St. Louis, USA) and centrifuged for $5 \mathrm{~min}$ at $200 \mathrm{~g}$ at room temperature to form one spheroid. Cells were then incubated at $37^{\circ} \mathrm{C}$ and $5 \%$ $\mathrm{CO}_{2}$ for 2 days.

\section{Preparation of the implants}

Cylindrical implants (Ø: $2 \mathrm{~mm}$, length: $2 \mathrm{~mm}$ ) were produced using fibrin gel (TISSEEL, Baxter, Frankfurt, Germany) containing $45 \mathrm{mg} / \mathrm{ml}$ of fibrinogen and 250 $\mathrm{IU} / \mathrm{ml}$ of thrombin. To prepare spheroid-loaded implants, $15 \mu \mathrm{l}$ of the fibrinogen solution were pipetted into $0.5 \mathrm{ml}$ tubes. Spheroids in the 96-well plate were washed once with PBS and then 1 spheroid (containing $5 \quad 10^{4}$ cells) was carefully transferred using a pipette tip into the $0.5 \mathrm{ml}$ tube. After adding $15 \mu \mathrm{l}$ of the thrombin solution, fibrin gels were allowed to polymerize for $30 \mathrm{~min}$ at $37^{\circ} \mathrm{C}$. Gels were carefully stirred using a $10 \mu \mathrm{l}$ pipette tip and incubated for another $30 \mathrm{~min}$.

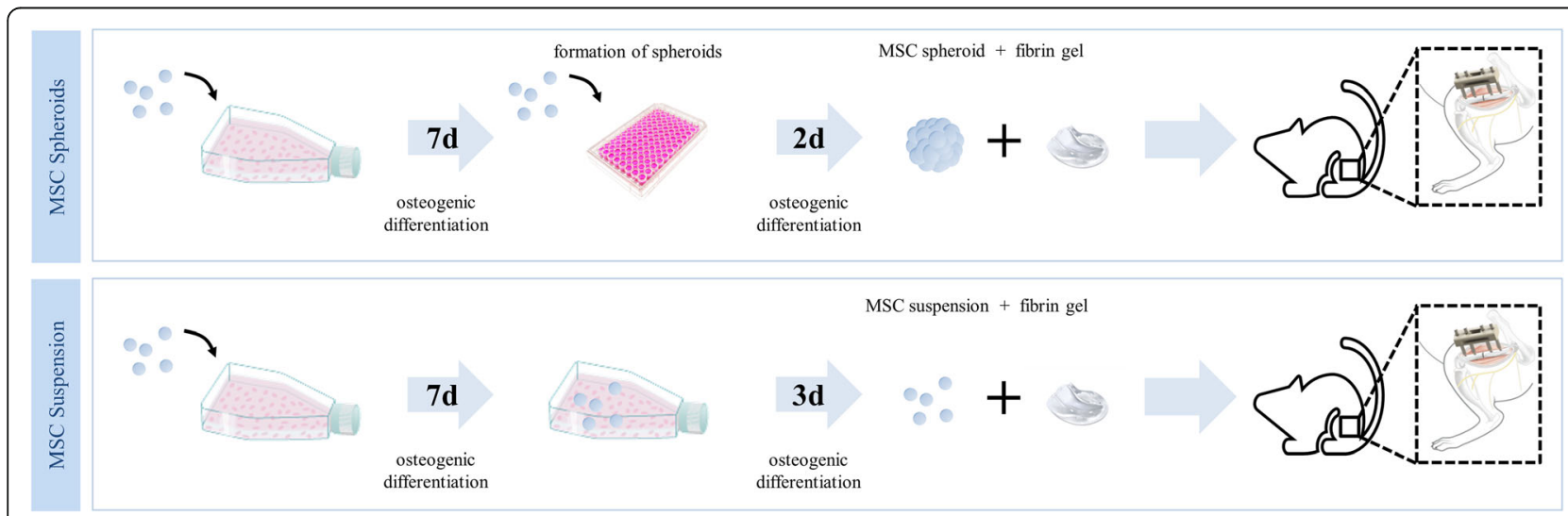

Fig. 1 Study design. MSCs were isolated from human bone marrow aspirates from healthy donors, divided into 2 groups: (1) MSC spheroids and (2) MSC suspensions and osteogenically pre-differentiated for 7 days. For spheroid formation, the detached MSC suspension was resuspended in osteogenic medium and transferred into 96-well suspension plates, followed by an incubation of 2 days. MSC suspensions were osteogenically differentiated in culture flasks for another 3 days. Then, $5 \quad 10^{4}$ cells - either as suspension or as spheroid - were immobilized within fibrin gels and implanted into a $2 \mathrm{~mm}$ segmental bone defect in the right femora of $26 \mathrm{nu} / \mathrm{nu}$ NOD/SCID nude mice that was stabilized by an external fixator. Animals were observed for 6 weeks. Afterwards, $\mu \mathrm{CT}$ and histological analyses were performed 
To prepare suspension-loaded implants, predifferentiated cells were detached from the culture flasks using $0.5 \%$ trypsin/EDTA, counted and resuspended in fibrinogen to a concentration of $3.3310^{6} / \mathrm{ml} .15 \mu \mathrm{l}$ of this cell suspension were mixed with $15 \mu \mathrm{L}$ thrombin solution and allowed to polymerize as mentioned above.

After polymerization, solid fibrin gels were transferred into $2 \mathrm{ml}$ tubes and immediately used for implantation. The number of spheroid- and suspension-loaded implants prepared from MSCs of the 4 individual donors that were implanted into the animals is shown in Table 1.

\section{Cell viability within implants}

Two additional implants per donor and group were prepared in the above-mentioned way and used - right after producing the implants - to check viability of cells before implantation by live/dead and MTT staining. For MTT staining that detects metabolic activity of cells, the implants were incubated with $0.5 \mathrm{mg} / \mathrm{ml} 3$-(4,5-dimethylthiazol-2-yl)-2,5-diphenyltetrazolium bromide (MTT, Sigma Aldrich, St. Louis, USA) in basic medium for up to $4 \mathrm{~h}$ at $37^{\circ} \mathrm{C}$. After washing with PBS, implants were fixed with $4 \%$ neutral buffered formaldehyde and imaged using a stereo microscope Leica M125 C (Leica Microsystems AG, Heerbrugg, Switzerland).

Live and dead cells within the implants were visualized using the Live/Dead Viability/Cytotoxicity Kit (ThermoFisher Scientific, Waltham, USA). Therefore, implants were washed once with PBS and subsequently incubated with $2.4 \mu \mathrm{M}$ calcein AM (live cells) and $2.4 \mu \mathrm{M}$ ethidium homodimer-1 (dead cells) in PBS. After light-protected incubation for $30 \mathrm{~min}$ at $37^{\circ} \mathrm{C}$, implants were washed once with PBS and cell viability was examined immediately using a Keyence BIOREVO BZ-9000 microscope (Keyence, Neu-Isenburg, Germany) with ex/em: $495 / 515 \mathrm{~nm}$ for calcein and $495 / 635 \mathrm{~nm}$ for ethidium homodimer-1.

\section{Animals}

For the in vivo study, 26 male, 14-15 weeks old nu/nu NOD/SCID nude mice $(35.8 \pm 3.2 \mathrm{~g})$ were randomized into 2 groups. The mice were bred at the Centre for Regenerative Therapies (CRTD), Technische Universität Dresden, fed with standard diet (food and water ad libitum) and kept at a 12-h light and dark cycle. All animal experiments were performed in accordance to the

Table 1 Number of implants prepared from the 4 individual MSC donors

\begin{tabular}{lllll}
\hline MSC implants & donor $\mathbf{1}$ & donor $\mathbf{2}$ & donor $\mathbf{3}$ & donor $\mathbf{4}$ \\
\hline spheroid-loaded implants & 3 & 3 & 3 & 3 \\
suspension-loaded implants & 3 & 4 & 3 & 4 \\
\hline
\end{tabular}

National Institutes of Health Guidelines for the Use of Experimental Animals and were approved by the Local Animal Care and Ethics Committee of Dresden University Hospital (protocol no. 24-9168.11-1/2013-75). All of the 26 animals survived the surgeries and the observation period.

\section{Surgical procedure}

Surgery was performed under $2 \%$ isoflurane anesthesia as described previously [27]. Additionally, each animal received $300 \mu$ l saline with $1.6 \mu \mathrm{g}$ buprenorphine as s. c. injection to minimalize pain. After placing the animal in prone position, a $12 \mathrm{~mm}$ incision was made along the lateral tight. To expose the femur, the incision was extended through the fascia lata, reaching from the great trochanter to the knee joint. Subsequently to the femur exposure and mobilization of muscles, an external fixator (MouseExFix simple XL, RISystem, Landquart, Switzerland) was placed by drilling pins into the lateral and medial cortex. The $2 \mathrm{~mm}$ defect was created with a $2 \mathrm{~mm}$ saw guide (RISystem) and Gigli wires $(0.22 \mathrm{~mm}$, RISystem). Thereafter, depending on the group allotment, implants were placed into the defect. Femur and surrounding tissue were relocated to their physiological position and the skin was closed by Donati suturing technique (Ethilon 4-0, Ethicon, Johnson \& Johnson, New Brunswick, NJ).

\section{Preparations for high-resolution micro-computed tomography and histology}

After 6 weeks of observation animals were sacrificed by exposure to $\mathrm{CO}_{2}$ following cervical dislocation. Right and left femora were dissected, cleaned from soft tissue and placed into $15 \mathrm{ml}$ tubes filled with $4 \%$ neutral buffered formaldehyde that was changed every 2 days. $\mu \mathrm{CT}$ scanning of all femora was performed under these conditions. To decalcify the bones, formaldehyde was replaced with EDTA. After dehydration using an ascending ethanol series, paraffin was used to embed the femora and samples were sagittally cut into slices of $2 \mu \mathrm{m}$.

\section{High-resolution micro-computed tomography - $\mu \mathrm{CT}$ analysis}

All femora were scanned with a SCANCO vivaCT 40 (Scanco Medical AG, Wangen-Brüttisellen, Switzerland). According to the manufacturer's instructions, the following calibration steps were performed: 5 rods of different hydroxyapatite densities were scanned once per week. To additionally check the alignment of the device, 3 aluminium wires were scanned once per month.

The following $\mu \mathrm{CT}$ settings were used to scan the mice femora: X-ray intensity $=145 \mu \mathrm{A}, \mathrm{X}$-ray tube $=55 \mathrm{kVp}$, voxel size $=21 \mu \mathrm{m}$, integration time $=200 \mathrm{~ms}$, projections $=1000$. 
Analysis was performed by using the software of the SCANCO vivaCT 40. Therefore, a standardized 3Dregion of interest with cylindrical shape (Ø: $2.5 \mathrm{~mm}$, length: $3.5 \mathrm{~mm}$ ) was determined with setting the centre between the inner 2 pins of the external fixator. Bone tissue density was defined as $>200 \mathrm{mg}$ hydroxyapatite/ $\mathrm{cm}^{3}$ and bone volume was measured in $\mathrm{mm}^{3}$.

\section{Histological examination}

All histological sections were evaluated using a Keyence BIOREVO BZ-9000 microscope (Keyence, NeuIsenburg, Germany).

Firstly, the grade of defect healing according to Huo et al. was classified by 3 different, blinded observers [29]. Therefore, tissue sections were stained with haematoxylin and eosin (H\&E, Merck, Darmstadt, Germany) and 3 representative sections per femur were assessed.

Secondly, vascularization and bone cell markers of the defect area were analysed. The area of interest was standardised by detecting the area between the inner pin holes with a $2 \mathrm{x}$ objective and separating it in 12 squares with the software of the microscope (BZ-II Viewer, Keyence, Neu-Isenburg, Germany).

To evaluate vascularization, alpha-smooth muscle actin staining (rabbit anti-smooth muscle actin, 1:750, Cat.\# M0851, Agilent Dako, Santa Clara, USA) was used. Vessels in the defect area showing a lumen were counted, vessels in the surrounding muscle and soft tissue were omitted.

To evaluate bone cell markers, slides were stained with bone alkaline phosphatase (BAP, anti-rabbit IgG peroxidase, 1:100, Cat.\# PAK0142, LINARIS Biologische Produkte $\mathrm{GmbH}$, Dossenheim, Germany) for osteoblasts and tartrate resistant acid phosphatase (TSP, SigmaAldrich, St. Louis, USA) for osteoclasts. Number of osteoclasts and osteoblasts were counted.

\section{Statistics}

Statistical analysis was done using GraphPad Prism 5.00 software (San Diego, CA, USA). All data are presented as mean \pm standard deviation. For bone volume, bone mineral density, number of osteoblasts and osteoclasts and vascularization differences between the 2 groups were tested using the 2-sided unpaired Student's test (normally distributed data) whereas its non-parametric equivalent Mann-Whitney test was applied for the histological degree of defect healing. The level of significance was set at $p=0.05$.

\section{Results}

\section{Cell viability within implants prior implantation}

As observed by MTT and live-dead staining spheroid as well as suspended cells showed good viability within the fibrin gel implants (Fig. 2).

\section{$\mu \mathrm{CT}$ analysis}

After a 6 weeks observation period, $\mu \mathrm{CT}$ analysis was performed to investigate the volume of the newly regenerated bone as well as bone mineral density (Fig. 3). Bone volume showed no intergroup difference in and around the defect area (MSC spheroids vs. MSC suspensions; $2.1 \pm 0.2 \mathrm{~mm}^{3}$ vs. $2.1 \pm 0.2 \mathrm{~mm}^{3}, p=0.9443$ ). However, treating the defect with spheroid-loaded implants led to a significantly increased bone mineral density at the defect side $\left(917 \pm 9 \mathrm{mgHA} / \mathrm{cm}^{3}\right)$ as compared to the suspension-loaded implants $\left(882 \pm 14 \mathrm{mgHA} / \mathrm{cm}^{3}\right.$, $p=0.043$ ). A systematic bias could be excluded since the difference between the bone mineral density of the unoperated femora of both groups was not significant (Additional File 1).

\section{Histological analysis}

Representative slides for each group and staining are shown in Fig. 4.

\section{Histological degree of defect healing}

Due to the numerical scoring schema of Huo et al. for histological analysis of fracture healing, a refined evaluation of the actual bone tissue healing can be achieved. Constant with the bone volume results of the $\mu \mathrm{CT}$ analysis, no difference in the degree of defect healing between the groups (MSC spheroids vs. MSC suspensions; $5.77 \pm 1.04$ vs. $5.95 \pm 1.12 ; p=0.1231$ ) could be shown (Fig. 5a). Additionally, no bridging of the defect area of any dissected femora could be seen.

\section{Histological analysis of bone cell markers and vascularization}

To investigate bone cell markers, the number of osteoblasts and osteoclasts were counted in the defect area (Fig. 5b - d). Neither the number of osteoblasts (MSC spheroids vs. MSC suspensions; $38.69 \pm 13.24$ vs. $49.31 \pm$ 14.43 cells/field; $p=0.0721$ ), nor the number of osteoclasts (MSC spheroids vs. MSC suspensions; $8.54 \pm 3.73$ vs. $10.46 \pm 2.60$ cells/field; $p=0.2113$ ) was significantly influenced by the condition of the cells within the implants. Furthermore, the vascularization seemed to be independent from the kind of MSC condition (MSC spheroids vs. MSC suspensions; $38.46 \pm 11.65$ vs. $41.92 \pm$ 42.41 vessels/field; $p=0.7842$ ).

\section{Discussion}

We hypothesized that MSC spheroids have a higher bone regenerative potential than MSC suspensions when applied in a critical-sized, murine femoral defect. Therefore, $510^{4}$ osteogenically pre-differentiated human MSCs of 4 individual donors were immobilized within fibrin gels, either as 1 cell spheroid or as cell suspension, and implanted into $2 \mathrm{~mm}$ critical-sized femoral defects 


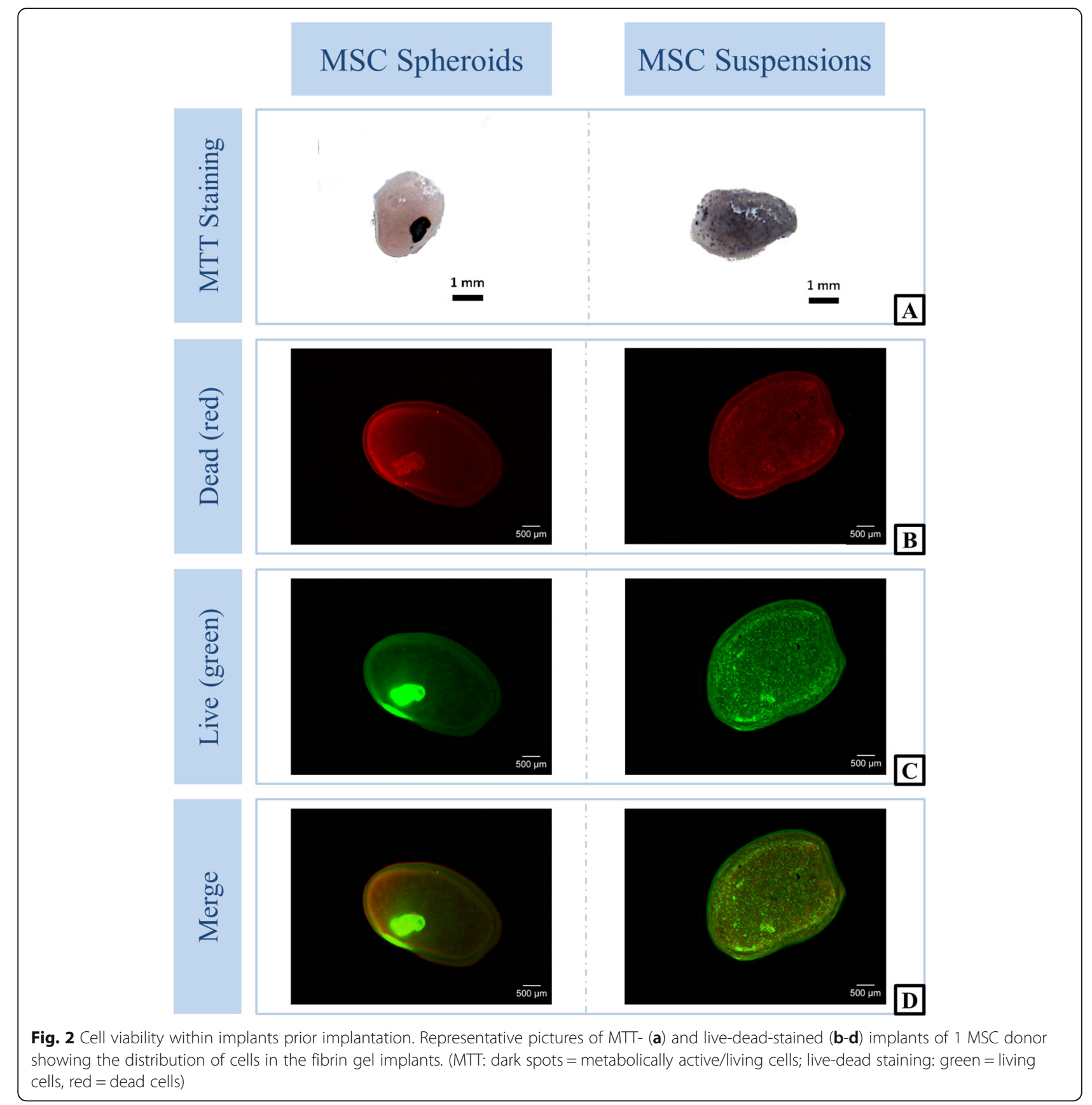

in mice. These immune deficient mice were especially chosen due to the implantation of human MSCs and to be in line with the study on which the critical-sized bone defect model was established. Previous studies also showed a regular bone growth and bone healing $[27,30]$.

Micro-CT analysis revealed a significantly higher bone density of the MSC spheroids group compared to the MSC suspensions group. MSC donor status did not correlate with bone mineral density and bone volume (Additional File 2). However, the regenerated bone volume at the defect side treated with MSC spheroids was comparable to the one treated with MSC suspensions. Additionally, histological analysis showed no significant differences regarding bone cell markers (number of osteoblasts and osteoclasts), as well as vascularization at the defect side for both groups.

Mesenchymal stromal cells can enhance the healing of bone defects due to their multilineage potential [31, 32]. In addition to that, MSC transplantation is beneficial to critical-sized bone defect healing because MSC attract other cells like osteoblasts and chondrocytes. Especially when exposed to hypoxic conditions, MSCs start to 
MSC spheroid - 3D reconstruction

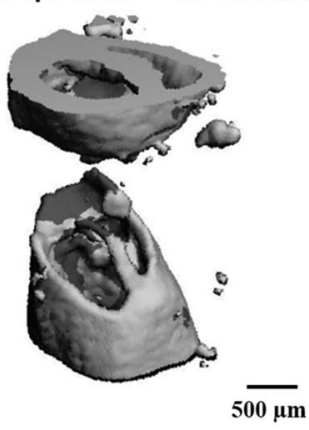

Bone Volume

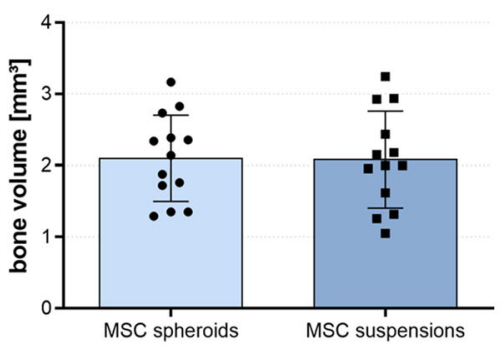

MSC suspension $-3 \mathrm{D}$ reconstruction

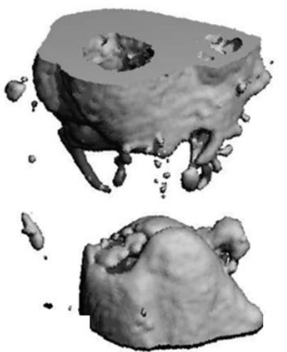

A

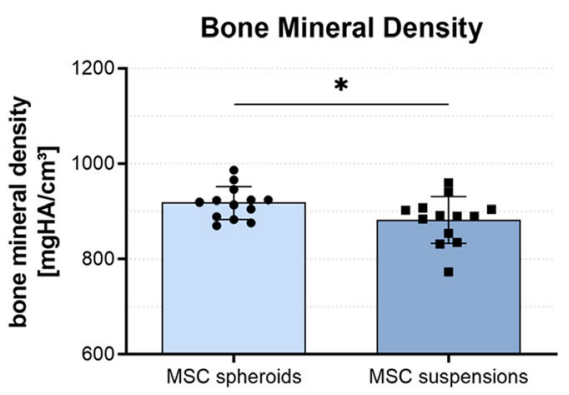

B

Fig. $3 \mu C T$-based evaluation of the defect area 6 weeks postoperatively. Representative 3D reconstruction of the defect area by high resolution $\mu \mathrm{CT}$ for MSC spheroids and suspensions (a) group. Bone volume (b) and bone mineral density (c) in the defect area as determined by $\mu \mathrm{CT}$. Whereas no intergroup difference could be observed for bone volume, MSC spheroids group showed a significantly higher bone mineral density than the MSC suspensions group (mean \pm SD; 2-sided Student's t-test, * $p<0.05$ )

secrete different cytokines [16]. MSCs are able to differentiate into multiple cell types such as fibroblasts, chondrocytes, adipocytes, and osteoblasts. To achieve a specific differentiation, cells must be treated with special media e.g. osteogenic medium to guide them to the osteogenic lineage [33, 34]. It was shown that both, spheroid and suspension cells, differentiate into osteoprogenitor cells [16, 23]. The success of culturing MSCs adequately depends on several factors including seeding density and pressure, thus, the same number of cells and seeding conditions were used in each group [35].

Furthermore, our previous studies on MSCs isolated from bone marrow, using the same procedure as the current study, could confirm the expression of mesenchymal stem cell markers and their trilineage differentiation potential $[36,37]$. When MSCs are immobilized within spheroids, several in vitro tests, which were performed by Yamaguchi et al., showed an upregulation of the osteogenic marker genes RUNX-2, OSX, BSP and OPN as compared to monolayer cultured cells [16, 38]. Furthermore, as mentioned by Cesarz et al., MSC spheroids show an enhanced multidifferentiation potential and upregulation of pluripotency marker genes indicating enhanced stemness.

Previously, 2D culture has been commonly used to obtain osteoblasts for bone healing in multiple studies.
However, these culturing techniques do not imitate the physiological microenvironment in vivo unlike culturing cells as spheroids $[20,21,39]$. Simulating the native morphology with a spheroid morphology, greater cellcell contacts are formed leading to anti-inflammatory und anti-apoptotic effects [18, 22].

As described by Yagamuchi et al., $510^{4}$ cells were used and spheroids were formed successfully and immobilized within fibrin gels [16]. Good viability of fibrin gel-encapsulated cells was demonstrated with MTT and live-dead staining, prior to implantation.

Fibrin gel was chosen to immobilize the cells in the bone defect due to its osteopromotive properties which influence the osteogenic potential of MSC suspension, as well as of MSC spheroids [17]. Tisseel is a clinically approved tissue sealant, can be applied minimal invasively, polymerizes fast, offers shape variability, compressive stiffness, degrades in vivo due to its similarity to physiological blood clots within around 7 days, provides a comfortable environment for the cells and allows them to immigrate [40-42]. Yet, fibrin gel does not replicate the mineralized compound and nanostructure of bone. In order to enhance mineral content, hydroxyapatite can be incorporated into fibrin gel. These scaffolds showed 


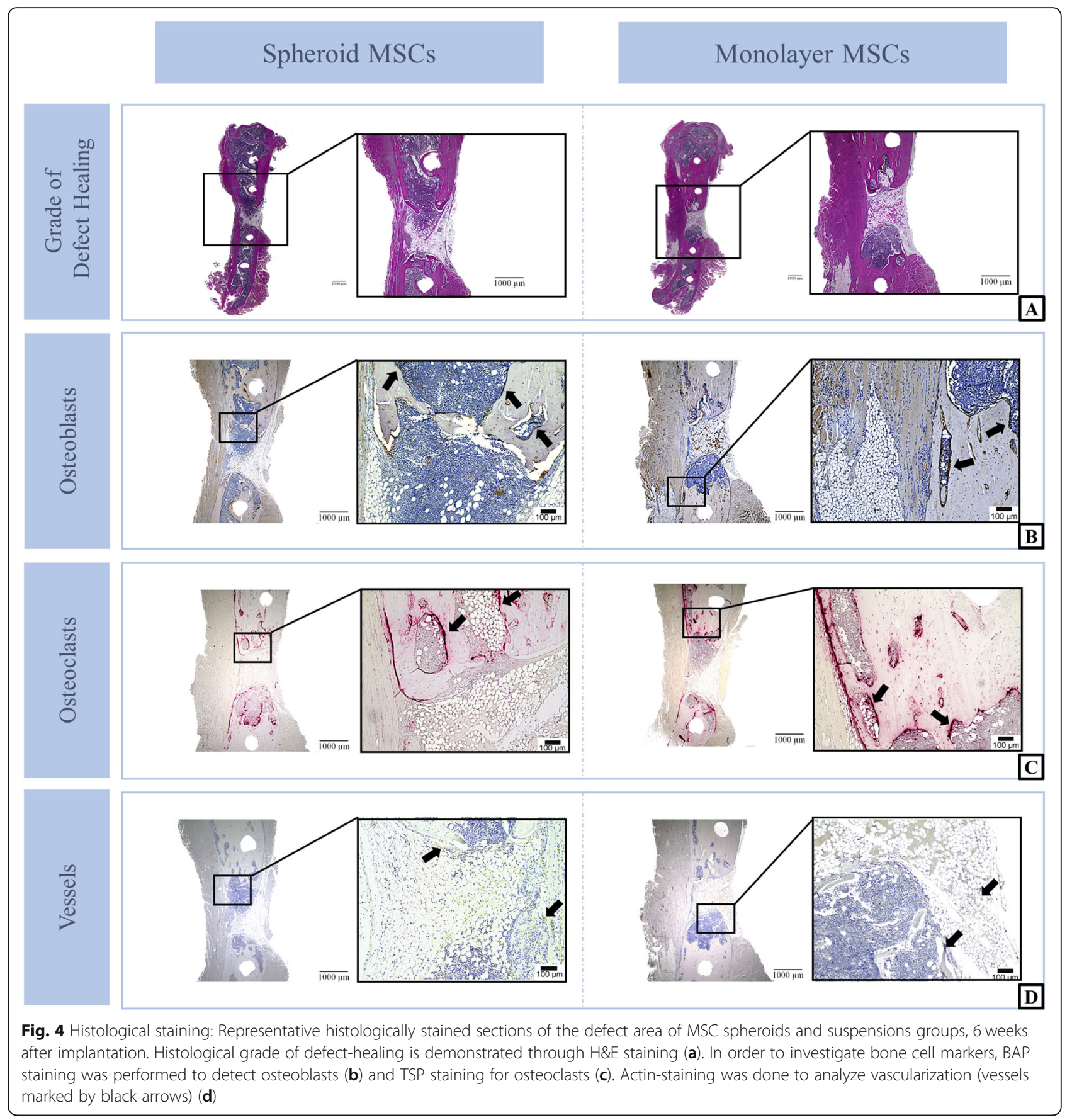

improved defect healing $[43,44]$. However, the adhesivity should be improved, since limited cell migration of MSC spheroids leads to increased bone formation [44]. Alternatively, mineralized collagen matrix scaffolds (MCM) are a suitable substrate for MSCs [28]. By comparing our findings, in particular those referring to bone volume (MSC spheroids: $2.1 \pm 0.2 \mathrm{~mm}^{3}$; MSC suspensions: $2.1 \pm 0.2 \mathrm{~mm}^{3}$ ), to Bolte et al. (MCM only: $3.9 \pm$ $2.0 \mathrm{~mm}^{3} ; \quad$ MCM + pre-differentiated $\quad$ MSCs: $\quad 6.3 \pm 1.3$ $\mathrm{mm}^{3}$ ), one concludes that not only pre-differentiation of
MSCs, but also the type of scaffold has a significant impact on bone healing [28].

The defect into which the MSCs were implanted can be described as critical-sized since $37.5 \%$ of animals with a defect size of $2 \mathrm{~mm}$ showed no bridging as observed in a study performed by Zwingenberger et al. [27]. In line with Bolte et al. and Quade et al. we also used a $2 \mathrm{~mm}$ defect for testing our hypothesis [28, 45]. After 6 weeks of observation, the bone density of the spheroid group was increased, which might be explained by upregulated 


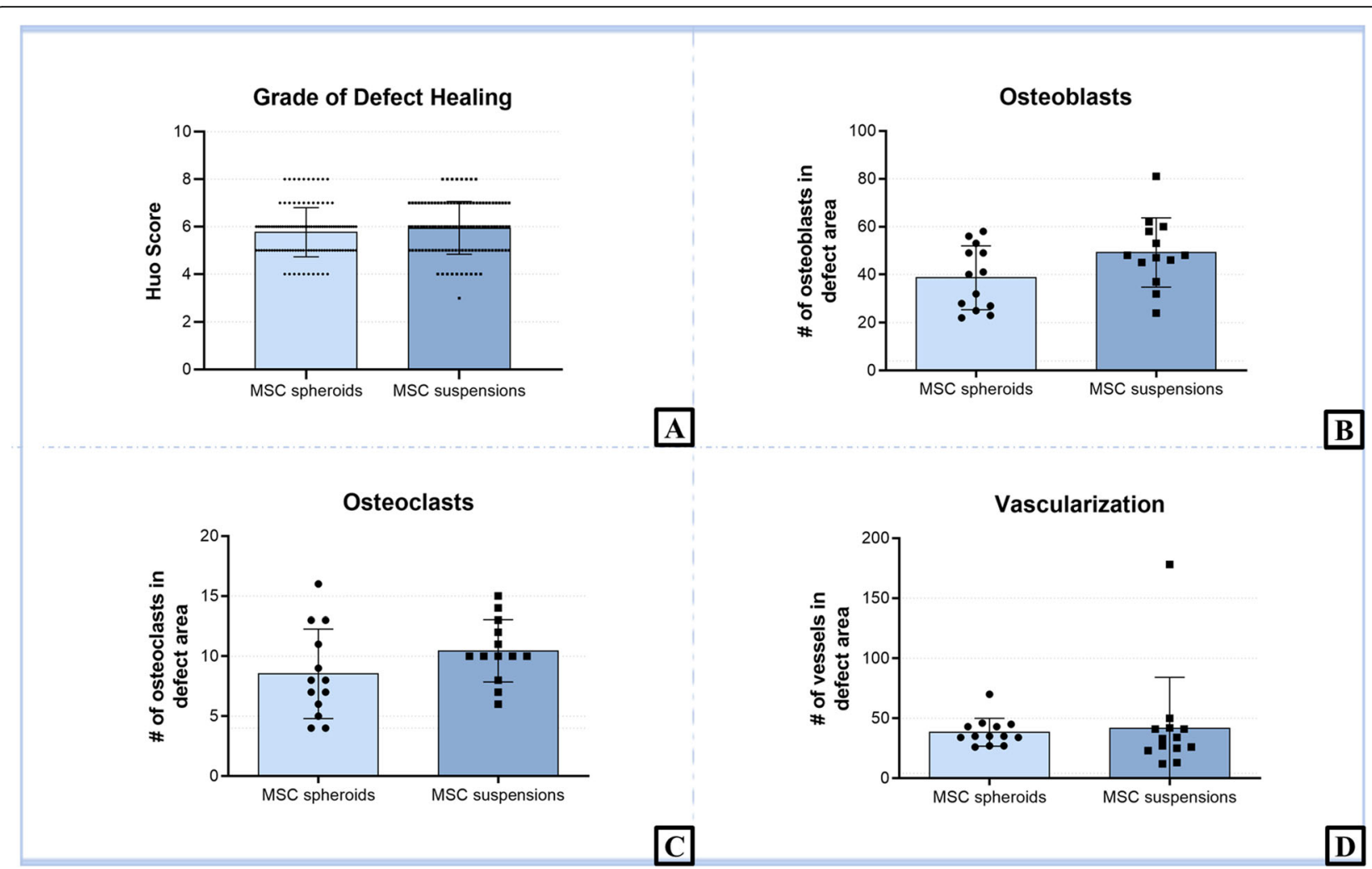

Fig. 5 Histological analysis of bone cell markers and vascularization: To grade the defect healing (a), 3 stained sections per animal were observed by 3 blinded observers and rated according to Huo et al. [29] (mean \pm SD, Mann-Whitney test). To investigate bone cell markers and vascularization, number of osteoblasts $(\mathbf{b})$, osteoclasts $(\mathbf{c})$, and vessels $(\mathbf{d})$ were counted in the defect area 6 weeks after implantation (mean \pm SD, 2-sided Student's t-test). No significant difference could be shown between the groups

levels of expression of osteogenic genes in MSC spheroids, as observed in vitro by Yagamuchi et al. Besides, spheroids have an enhanced survival rate under ischemic conditions compared to suspended cells [24].

However, an increased healing of the defect by MSC spheroids was not shown as opposed to the application of osteoinductive materials like BMP-2 or using a 2-step stem cell therapy $[28,45,46]$.

Limitations of this study are the usage of one spheroid containing $510^{4}$ cells per implant due to technical reasons, leading to deficiencies of inter-spheroidal cell communication. Spheroids consisting of more than 15,000 cells result in diameters larger than $200 \mu \mathrm{m}$ [17, 47]. Thus, limitations of diffusion and nutrient transport might be exceeded, creating hypoxia in the core of the spheroid [47]. Caspase activity is thereby upregulated, indicating a higher level of apoptosis [17]. Despite the high cell viability within the spheroid immediately prior to implantation, as observed by MTT and live-dead staining, this effect of hypoxia might increase over time when cells are implanted. On the other hand, there is evidence that a hypoxic core might enhance cell survival and secretion of trophic factors [48, 49]. Additionally, it has been shown that larger spheroids secret more prostaglandin E2 and vascular endothelial growth factor than smaller spheroids, which can stimulate defect healing advantageously [21].

For further investigations regarding the osteoregenerative potential of MSC spheroids, smaller spheroids containing less cells might be used. Alternatively, the gravity-driven hanging drop method could be applied as a spheroid formation technique due to its ease of use, lack of specialized equipment and utility for small spheroids $[44,50]$. As a next step, genetically modified MSC spheroids showing an enhanced upregulation of migration-related genes and maintaining these qualities through pathological conditions could be implanted into critical-sized defects [51]. One could also pre-culture MSCs under hypoxic conditions that enhance therapeutic effects of spheroids [51]. Further improvements in the culture methods of MSC spheroids cultivation might prove useful to bone regeneration.

\section{Conclusion}

With regards to the regenerated bone volume, it was shown that MSC spheroids are comparable to MSC suspensions for the treatment of a critical-sized bone defect. In contrast, using MSC spheroids led to an increased 
bone mineral density which could be beneficial for older patients with osteoporosis or deficient bone healing capacity. However, the osteoinductive potency of the investigated cells alone - independent from their appearance within the implant - is insufficient for healing large bone defects in contrast to established clinical methods such as autograft bone. Future improvements of MSC spheroids might lead to greater bone regenerative potential such that the limited therapeutic options of criticalsized bone defects could be successfully replaced.

\section{Supplementary Information}

The online version contains supplementary material available at https://doi. org/10.1186/s12891-021-04264-y.

Additional file 1. Difference between left and right femora.

Additional file 2. MSC donor's effect.

\section{Acknowledgements}

We are grateful to Maik Stiehler for providing the bone marrow aspirates. We also thank Suzanne Manthey and Annett Wenke for preparing the histological sections as well as Tilman von Strauwitz for supporting the image editing process.

\section{Authors' contributions}

L. F.: substantial contribution to analysis and interpretation of the data, drafting the paper. J. B.: substantial contribution to acquisition, analysis, and interpretation of the data, drafting the paper, and revising it critically. C. V.: substantial contribution to research design, data acquisition, analysis and interpretation, drafting the paper, and revising it critically. C. P.: substantial contribution to data acquisition, analysis and interpretation. M. Q.: substantial contribution to data acquisition, analysis and interpretation. L. M.: substantial contribution to data acquisition, analysis and interpretation. S. B. G.: substantial contribution to research design, drafting the paper, and revising it critically. S. Z: substantial contribution to research design, data acquisition, analysis and interpretation, drafting the paper, and revising it critically. All authors have read and approved the final submitted manuscript.

\section{Funding}

This research received no specific grant from any funding agency in the public, commercial or not-for-profit sectors. Open Access funding enabled and organized by Projekt DEAL.

\section{Availability of data and materials}

The datasets used and analyzed during the current study are available from the corresponding author on reasonable request.

\section{Declarations}

Ethics approval and consent to participate

The MSCs isolation was performed with the appropriate participant's informed consent in compliance with the Helsinki Deceleration and was approved by local ethical review committee of the Technical University Dresden (ethics approval number: EK91032012). All animal experiments were performed in accordance to the National Institutes of Health Guidelines for the Use of Experimental Animals and were approved by the Local Animal Care and Ethics Committee of Dresden University Hospital (protocol no. 249168.11-1/2013-75)

All methods are reported in accordance with ARRIVE guidelines for the reporting of animal experiments.

\section{Consent for publication}

Not applicable.

\section{Competing interests}

The authors declare that they have no competing interests.

\section{Author details}

'University Center for Orthopedic, Trauma and Plastic Surgery, University Hospital Carl Gustav Carus, TU Dresden, Dresden, Germany. ${ }^{2}$ Center for Translational Bone, Joint and Soft Tissue Research, University Medicine Carl Gustav Carus Dresden, TU Dresden, Dresden, Germany. ${ }^{3}$ Department of Orthopedic Surgery, Stanford University, Stanford, USA.

Received: 1 December 2020 Accepted: 12 April 2021

Published online: 30 April 2021

\section{References}

1. Laurencin C, Khan Y, El-Amin SF. Bone graft substitutes. Expert Rev Med Devices. 2006;3(1):49-57. https://doi.org/10.1586/17434440.3.1.49.

2. Perry CR. Bone Repair Techniques, Bone Graft, and Bone Graft Substitutes. Clin Orthop. 1999;360:71-86.

3. Fleming JE, Cornell CN, Muschler GF. Bone cells and matrices in orthopedic tissue engineering. Orthop Clin North Am. 2000;31(3):357-74. https://doi. org/10.1016/50030-5898(05)70156-5.

4. Friedenstein AJ, Chailakhyan RK, Latsinik NV, Panasyuk AF, Keiliss-Borok IV. Stromal cells responsible for transferring the microenvironment of the hemopoietic tissues: cloning in vitro and retransplantation in vivo. Transplantation. 1974;17(4):331-40. https://doi.org/10.1097/00007890-1 97404000-00001.

5. Campagnoli C, Roberts IAG, Kumar S, Bennett PR, Bellantuono I, Fisk NM. Identification of mesenchymal stem/progenitor cells in human first-trimester fetal blood, liver, and bone marrow. Blood. 2001;98(8):2396-402. https://doi. org/10.1182/blood.V98.8.2396.

6. Erices $\mathrm{A}$, Conget $\mathrm{P}$, Minguell J. Mesenchymal progenitor cells in human umbilical cord blood. Br J Haematol. 2000;109(1):235-42. https://doi.org/10.1 046/j.1365-2141.2000.01986.x.

7. Zuk PA, Zhu M, Ashjian P, De Ugarte DA, Huang Jl, Mizuno H, et al. Human adipose tissue is a source of multipotent stem cells. Mol Biol Cell. 2002; 13(12):4279-95. https://doi.org/10.1091/mbc.e02-02-0105.

8. Reddi AH, Cunningham NS. Recent Progress in bone induction by Osteogenin and bone morphogenetic proteins: challenges for biomechanical and tissue engineering. J Biomech Eng. 1991;113(2):189-90. https://doi.org/10.1115/1.2891233.

9. Prockop DJ, Phinney DG, Bunnell BA, editors. Mesenchymal stem cells: methods and protocols. Totowa, NJ: Humana Press; 2008. https://doi.org/1 0.1007/978-1-60327-169-1.

10. Bronckaers A, Hilkens P, Martens W, Gervois P, Ratajczak J, Struys T, et al. Mesenchymal stem/stromal cells as a pharmacological and therapeutic approach to accelerate angiogenesis. Pharmacol Ther. 2014;143(2):181-96. https://doi.org/10.1016/j.pharmthera.2014.02.013.

11. Bruder SP, Jaiswal N, Haynesworth SE. Growth kinetics, self-renewal, and the osteogenic potential of purified human mesenchymal stem cells during extensive subcultivation and following cryopreservation. J Cell Biochem. 1997:64(2):278-94. https://doi.org/10.1002/(SICI)1097-4644(199702)64:2< 278::AID-JCB11>3.0.CO;2-F.

12. Lee S, Choi E, Cha M-J, Hwang K-C. Cell adhesion and long-term survival of transplanted Mesenchymal stem cells: a prerequisite for cell therapy. Oxidative Med Cell Longev. 2015;2015:1-9. https://doi.org/10.11 55/2015/632902.

13. Zhang M, Methot D, Poppa V, Fujio Y, Walsh K, Murry CE. Cardiomyocyte grafting for cardiac repair: graft cell death and anti-death strategies. J Mol Cell Cardiol. 2001;33(5):907-21. https://doi.org/10.1006/jmcc.2001.1367.

14. Reya T, Morrison SJ, Clarke MF, Weissman IL. Stem cells, cancer, and cancer stem cells. Nature. 2001;414(6859):105-11. https://doi.org/10.1038/35102167.

15. Colter DC, Class R, DiGirolamo CM, Prockop DJ. Rapid expansion of recycling stem cells in cultures of plastic-adherent cells from human bone marrow. Proc Natl Acad Sci. 2000;97(7):3213-8. https://doi.org/10.1 073/pnas.97.7.3213.

16. Yamaguchi Y, Ohno J, Sato A, Kido H, Fukushima T. Mesenchymal stem cell spheroids exhibit enhanced in-vitro and in-vivo osteoregenerative potential. BMC Biotechnol. 2014;14(1):105. https://doi.org/10.1186/s12896-014-0105-9.

17. Murphy KC, Fang SY, Leach JK. Human mesenchymal stem cell spheroids in fibrin hydrogels exhibit improved cell survival and potential for bone healing. Cell Tissue Res. 2014;357(1):91-9. https://doi.org/10.1007/s00441014-1830-z.

18. Ho SS, Murphy KC, Binder BYK, Vissers CB, Leach JK. Increased survival and function of Mesenchymal stem cell spheroids entrapped in 
instructive alginate hydrogels: enhanced spheroid function in engineered hydrogels. Stem Cells Transl Med. 2016;5(6):773-81. https:// doi.org/10.5966/sctm.2015-0211.

19. Santos JM, Camões SP, Filipe E, Cipriano M, Barcia RN, Filipe M, et al. Threedimensional spheroid cell culture of umbilical cord tissue-derived mesenchymal stromal cells leads to enhanced paracrine induction of wound healing. Stem Cell Res Ther. 2015;6(1):90. https://doi.org/10.1186/ s13287-015-0082-5.

20. Wang C-C, Chen C-H, Hwang S-M, Lin W-W, Huang C-H, Lee W-Y, et al. Spherically symmetric Mesenchymal stromal cell bodies inherent with endogenous extracellular Matrices for cellular Cardiomyoplasty. Stem Cells. 2009;27(3):724-32. https://doi.org/10.1634/stemcells.2008-0944.

21. YIÖstalo JH, Bartosh TJ, Coble K, Prockop DJ. Human Mesenchymal stem/ stromal cells cultured as spheroids are self-activated to produce prostaglandin E2 that directs stimulated macrophages into an anti-inflammatory phenotype: hMSC spheroids promote M2 macrophage phenotype. Stem Cells. 2012;30(10):2283-96. https://doi.org/10.1002/stem.1191.

22. Bartosh TJ, Ylostalo JH, Mohammadipoor A, Bazhanov N, Coble K, Claypool $\mathrm{K}$, et al. Aggregation of human mesenchymal stromal cells (MSCs) into 3D spheroids enhances their antiinflammatory properties. Proc Natl Acad Sci. 2010;107(31):13724-9. https://doi.org/10.1073/pnas.1008117107.

23. Murphy KC, Hoch Al, Harvestine JN, Zhou D, Leach JK. Mesenchymal stem cell spheroids retain Osteogenic phenotype through $\alpha_{2} \beta_{1}$ signaling: MSC spheroids retain Osteogenic phenotype. Stem Cells Transl Med. 2016;5(9): 1229-37. https://doi.org/10.5966/sctm.2015-0412.

24. Bhang SH, Lee S, Shin J-Y, Lee T-J, Kim B-S. Transplantation of cord blood Mesenchymal stem cells as spheroids enhances vascularization. Tissue Eng Part A. 2012;18(19-20):2138-47. https://doi.org/10.1089/ten.tea.2011.0640.

25. Roddy E, DeBaun MR, Daoud-Gray A, Yang YP, Gardner MJ. Treatment of critical-sized bone defects: clinical and tissue engineering perspectives. Eur J Orthop Surg Traumatol. 2018;28(3):351-62. https://doi.org/10.1007/s00590017-2063-0.

26. Clough BH, McCarley MR, Gregory CA. A Simple Critical-sized Femoral Defect Model in Mice. J Vis Exp. 2015:(97).

27. Zwingenberger S, Niederlohmann E, Vater C, Rammelt S, Matthys R, Bernhardt $\mathrm{R}$, et al. Establishment of a femoral critical-size bone defect model in immunodeficient mice. J Surg Res. 2013;181(1):e7-14. https://doi. org/10.1016/j.jss.2012.06.039.

28. Bolte J, Vater C, Culla AC, Ahlfeld T, Nowotny J, Kasten P, et al. Two-step stem cell therapy improves bone regeneration compared to concentrated bone marrow therapy. J Orthop Res Off Publ Orthop Res Soc. 2019;37(6): 1318-28. https://doi.org/10.1002/jor.24215.

29. Huo MH, Troiano NW, Pelker RR, Gundberg CM, Friedlaender GE. The influence of ibuprofen on fracture repair: biomechanical, biochemical, histologic, and histomorphometric parameters in rats. J Orthop Res. 1991; 9(3):383-90. https://doi.org/10.1002/jor.1100090310.

30. Ho Yue Gan J. Characterisation of Bone Defect Models in Immunodeficient Animals; 2005

31. Wang X, Wang C, Gou W, Xu X, Wang Y, Wang A, et al. The optimal time to inject bone mesenchymal stem cells for fracture healing in a murine model. Stem Cell Res Ther. 2018;9(1):272. https://doi.org/10.1186/s13287-018-1034-7.

32. Kalervo VH. Mesenchymal stem cells. Ann Med. 2005;37(7):469-79. https:// doi.org/10.1080/07853890500371957.

33. Heng BC, Cao T, Stanton LW, Robson P, Olsen B. Strategies for directing the differentiation of stem cells into the Osteogenic lineage in vitro. J Bone Miner Res. 2004;19(9):1379-94. https://doi.org/10.1359/JBMR.040714.

34. Song I-H, Caplan Al, Dennis JE. In vitro dexamethasone pretreatment enhances bone formation of human mesenchymal stem cells in vivo. J Orthop Res. 2009;27(7):916-21. https://doi.org/10.1002/jor.20838.

35. Pittenger MF. Multilineage potential of adult human Mesenchymal stem cells. Science. 1999;284(5411):143-7. https://doi.org/10.1126/science.284. 5411.143.

36. Stiehler M, Rauh J, Bünger C, Jacobi A, Vater C, Schildberg T, et al. In vitro characterization of bone marrow stromal cells from osteoarthritic donors. Stem Cell Res. 2016;16(3):782-9. https://doi.org/10.1016/j.scr.2016.03.013.

37. Sacks D, Baxter B, Campbell BCV, Carpenter JS, Cognard C, Dippel D, et al. Multisociety consensus quality improvement revised consensus statement for endovascular therapy of acute ischemic stroke. Int I Stroke Off J Int Stroke Soc. 2018;13:612-32.

38. Cesarz Z Tamama K. Spheroid culture of Mesenchymal stem cells. Stem Cells Int. 2016;2016:9176357.
39. Baraniak PR, McDevitt TC. Scaffold-free culture of mesenchymal stem cell spheroids in suspension preserves multilineage potential. Cell Tissue Res. 2012;347(3):701-11. https://doi.org/10.1007/s00441-011-1215-5.

40. Janmey PA, Winer JP, Weisel JW. Fibrin gels and their clinical and bioengineering applications. J R Soc Interface. 2009;6(30):1-10. https://doi. org/10.1098/rsif.2008.0327.

41. Barsotti MC, Magera A, Armani C, Chiellini F, Felice F, Dinucci D, et al. Fibrin acts as biomimetic niche inducing both differentiation and stem cell marker expression of early human endothelial progenitor cells. Cell Prolif. 2011; 44(1):33-48. https://doi.org/10.1111/j.1365-2184.2010.00715.x.

42. Davis HE, Miller SL, Case EM, Leach JK. Supplementation of fibrin gels with sodium chloride enhances physical properties and ensuing osteogenic response. Acta Biomater. 2011;7(2):691-9. https://doi.org/10.1 016/j.actbio.2010.09.007

43. Fricain JC, Schlaubitz S, Le Visage C, Arnault I, Derkaoui SM, Siadous R, et al. A nano-hydroxyapatite - Pullulan/dextran polysaccharide composite macroporous material for bone tissue engineering. Biomaterials. 2013;34(12): 2947-59. https://doi.org/10.1016/j.biomaterials.2013.01.049.

44. Gionet-Gonzales MA, Leach JK. Engineering principles for guiding spheroid function in the regeneration of bone, cartilage, and skin. Biomed Mater. 2018;13(3):034109. https://doi.org/10.1088/1748-605X/aab0b3.

45. Quade M, Vater C, Schlootz S, Bolte J, Langanke R, Bretschneider $H$, et al. Strontium enhances BMP-2 mediated bone regeneration in a femoral murine bone defect model. J Biomed Mater Res B Appl Biomater. 2020; 108(1):174-82. https://doi.org/10.1002/jbm.b.34376.

46. Schmidmaier G, Capanna R, Wildemann B, Beque T, Lowenberg D. Bone morphogenetic proteins in critical-size bone defects: what are the options? Injury. 2009;40:S39-43. https://doi.org/10.1016/S0020-1383(09)70010-5.

47. Curcio E, Salerno S, Barbieri G, De Bartolo L, Drioli E, Bader A. Mass transfer and metabolic reactions in hepatocyte spheroids cultured in rotating wall gas-permeable membrane system. Biomaterials. 2007;28(36):5487-97. https://doi.org/10.1016/j.biomaterials.2007.08.033.

48. Korff T, Augustin HG. Integration of endothelial cells in multicellular spheroids prevents apoptosis and induces differentiation. J Cell Biol. 1998; 143(5):1341-52. https://doi.org/10.1083/jcb.143.5.1341.

49. Shweiki D, Neeman M, Itin A, Keshet E. Induction of vascular endothelial growth factor expression by hypoxia and by glucose deficiency in multicell spheroids: implications for tumor angiogenesis. Proc Natl Acad Sci. 1995; 92(3):768-72. https://doi.org/10.1073/pnas.92.3.768.

50. Foty R. A simple hanging drop cell culture protocol for generation of 3D spheroids. J Vis Exp. 2011. https://doi.org/10.3791/2720.

51. Yanagihara K, Uchida S, Ohba S, Kataoka K, Itaka K. Treatment of bone defects by transplantation of genetically modified Mesenchymal stem cell spheroids. Mol Ther - Methods Clin Dev. 2018;9:358-66. https://doi.org/10.1 016/j.omtm.2018.04.006.

\section{Publisher's Note}

Springer Nature remains neutral with regard to jurisdictional claims in published maps and institutional affiliations.

Ready to submit your research? Choose BMC and benefit from:

- fast, convenient online submission

- thorough peer review by experienced researchers in your field

- rapid publication on acceptance

- support for research data, including large and complex data types

- gold Open Access which fosters wider collaboration and increased citations

- maximum visibility for your research: over $100 \mathrm{M}$ website views per year

At $\mathrm{BMC}$, research is always in progress.

Learn more biomedcentral.com/submissions 